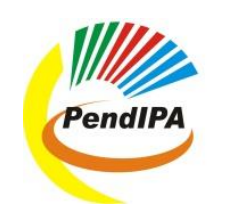

\title{
Upaya Meningkatkan Kecerdasan Budaya, Kompetensi Lintas Budaya dan Ketahanan bagi Peacekeeper dalam Misi Perdamaian PBB
}

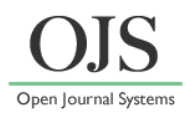

\author{
Ahmad Firdaus $^{1 *}$, Nour Zattullah ${ }^{2}$ \\ ${ }^{1}$ Program Pascasarjana Sekolah Tinggi Intelijen Negara \\ ${ }^{2}$ Universitas Pertahanan \\ *Email: yakuzablackn@gmail.com
}

DOI: https://doi.org/10.33369/pendipa.6.1.169-176

\begin{abstract}
Until early 2021, there were 12 UN peace missions carried out under the Department of Peace Operations. However, not all peace missions that have been carried out by the United Nations have been successful. One example of a UN peacekeeping mission that was judged to have failed was the United Nations Operations in Somalia (UNOSOM) I (1992-1993) and II (1993-1995) missions. One of the causes of the failure of the UNOSOM mission is because the mission cannot answer the challenges of cultural differences, both between peacekeepers and with locals. This research was conducted to elaborate efforts to increase cross cultural intelligence and resilience for peacekeepers and their families so that the missions that will be carried out by them in the future can produce better outcomes than before. This research used the qualitative research method. This study found that cultural intelligence and cross cultural competence are two important abilities that must be possessed by peacekeepers who work in different cultural environments. On the other hand, the potential for peacekeepers to be exposed to stress during assignments in conflict areas and the negative impacts that peacekeeper families may experience during their assignment also need to be a concern, both for the United Nations and peacekeeper sender countries. Both efforts to increase cultural intelligence, cross cultural competence to the resilience of peacekeepers and their families can be done through training. However, commitment and strong political will are needed from the relevant stakeholders so that these trainings can be carried out in a systematic, comprehensive, sustainable manner to support various peace missions that are still and will be carried out by the United Nations..
\end{abstract}

Keywords: peacekeeper; cultural intelligence; cross-cultural competence; resilience

\begin{abstract}
ABSTRAK
Hingga awal 2021, terdapat 12 misi perdamaian PBB yang dilaksanakan di bawah Department of Peace Operations. Namun demikian, tidak semua misi perdamaian yang pernah dilakukan oleh PBB berhasil. Salah satu contoh misi perdamaian PBB yang dinilai gagal adalah misi United Nations Operation in Somalia (UNOSOM) I (1992-1993) dan II (1993-1995). Salah satu penyebab kegagalan misi UNOSOM adalah karena misi tersebut tidak dapat menjawab tantangan berupa perbedaan kebudayaan yang ada, baik antar peacekeeper (pasukan misi pemeliharaan perdamaian $\mathrm{PBB}$ ) maupun dengan warga lokal. Penelitian ini dilakukan untuk mengelaborasi upaya untuk meningkatkan kecerdasan lintas budaya dan ketahanan bagi peacekeeper dan keluarganya agar misi-misi yang akan dilaksanakan oleh mereka di masa depan dapat menghasilkan outcome yang lebih baik daripada sebelumnya. Metode penelitian yang digunakan adalah metode penelitian kualitatif. Penelitian ini menemukan bahwa kecerdasan budaya dan kompetensi budaya merupakan dua kemampuan penting yang harus dimiliki oleh peacekeeper yang bertugas di lingkungan budaya yang berbeda. Di sisi lain, potensi peacekeeper terpapar stress selama penugasan di wilayah konflik dan dampak negatif yang mungkin dialami keluarga peacekeeper selama ia ditugaskan juga perlu menjadi perhatian, baik bagi PBB maupun negara-negara pengirim peacekeeper. Baik upaya peningkatan kecerdasan budaya, kompetensi lintas budaya hingga ketahanan peacekeeper dan keluarganya dapat dilakukan dengan pelatihan-pelatihan. Namun demikian, diperlukan komitmen dan kemauan politik yang kuat dari para stakeholder terkait agar pelatihan-pelatihan ini dapat dilaksanakan dengan sistematis,
\end{abstract}


komprehensif dan berkesinambungan untuk mendukung berbagai misi perdamaian yang masih dan akan dilaksanakan oleh PBB.

Kata kunci: peacekeeper; cultural intelligence; cross-cultural competence; resilience.

\section{PENDAHULUAN}

Konflik merupakan fenomena yang akan selalu terjadi dalam kehidupan manusia. Dalam kenyataannya, konflik bukan hanya terkait dengan perebutan kepentingan ekonomi dan kekuasaan, tetapi juga mengenai identitas dan nilai dari kelompok-kelompok yang berkonflik (Ho-Won, 2008). Seiring berjalannya waktu, konflik terus berkembang menjadi semakin kompleks. Salah satu jenis konflik yang muncul pasca era kolonialisme saat ini adalah konflik sosial internasional (international social conflicts), yaitu konflik yang bukan secara murni terjadi antar negara (interstate) dan bukan juga secara murni terjadi secara domestik, tetapi merupakan konflik yang berada di antara keduanya (Miall, Ramsbotham, \& Woodhouse, 2011). Jenis konflik seperti ini banyak terjadi di berbagai belahan dunia pasca era Perang Dingin, dimana menurut Huntington, konflik di periode ini tidak didominasi oleh konflik antar negara, melainkan antar kelompok dengan entitas tertentu, misalnya entitas budaya, agama maupun entitas lainnya (Huntington, 1996).

Beberapa konflik ini berlangsung berkepanjangan dan dengan intensitas kekerasan yang tinggi. Hal ini mendorong PBB membentuk sebuah misi untuk menjaga perdamaian (peacekeeping mission). Pada 15 November 1956, PBB pertama kali membentuk misi perdamaian dengan nama United Nations Emergency Force (UNEF) yang diterjunkan ke Sinai untuk menengahi konflik antara Mesir dan Israel. Pada 1992, PBB mendirikan Department of Peacekeeping Operations untuk menjalankan misi peacekeeping di seluruh dunia. Pada prinsipnya, misi perdamaian PBB dimaksudkan untuk memisahkan dua atau lebih pihak yang berkonflik dalam rangka mencegah berlanjutnya konflik kekerasan (Nye \& Welch, 2017).

Hingga awal 2021, terdapat 12 misi perdamaian PBB yang dilaksanakan di bawah Department of Peace Operations, yaitu di Sahara Barat, Republik Afrika Tengah, Mali, Kongo, Golan, Siprus, Lebanon, Abyei, Kosovo, Sudan Selatan, India \& Pakistan, serta Timur Tengah
(United Nations, 2021). Namun demikian, tidak semua misi perdamaian yang pernah dilakukan oleh PBB berhasil. Salah satu contoh misi perdamaian PBB yang dinilai gagal adalah misi United Nations Operation in Somalia (UNOSOM) I (1992-1993) dan II (1993-1995). Dalam pelaksanaan misi tersebut, koordinasi antar pasukan lintas negara dan komandannya di PBB sangat tidak efektif. Bantuan kemanusiaan untuk mengatasi kelaparan justru digunakan untuk 'menyuap' milisi yang dianggap kooperatif terhadap mereka. Di samping itu, marak terjadi penyerangan oleh milisi lokal terhadap pasukan PBB. Pada akhirnya, setelah muncul penolakan oleh pihak-pihak yang berkonflik, misi yang diwarnai dengan mismanagement dan korupsi tersebut diakhiri pada 1995 (Murray, 2021). Kegagalan misi UNOSOM di Somalia menunjukkan bahwa misi PBB yang didukung dengan biaya besar tidak menjamin keberhasilan. Tamara Duffey menyatakan bahwa salah satu penyebab kegagalan misi UNOSOM adalah karena misi tersebut tidak dapat menjawab tantangan berupa perbedaan kebudayaan yang ada, baik antar pasukan yang terdiri dari tentara negara yang berbeda-beda, antar militer-sipil, dan lebih parahnya, PBB tidak memahami budaya yang berlaku di Somalia (Duffey, 2000). Selain isu mengenai budaya, peacekeeping dalam era kontemporer juga perlu memperhatikan ketahanan (resilience) peacekeeper. Tidak dapat dipungkiri bahwa selama penugasan, peacekeeper rawan mengalami stress karena peristiwa traumatik yang dapat berdampak pada perilakunya sebagai individu maupun efektivitas organisasi yang diawakinya (Lamerson \& Kelloway, 1996). Di samping itu, penugasan peacekeeper yang berada di wilayah konflik juga berdampak pada ketahanan keluarganya. Penugasan ini secara umum berdampak pada peningkatan konflik dan kekerasan dalam keluarga, peningkatan kesalahan pola asuhan dan penelantaran anak, depresi, kecemasan dan trauma sekunder, serta peningkatan risiko permasalahan terhadap emosi 
dan perilaku anak-anak mereka (Saltzman, et al., 2011).

Melihat fakta-fakta di atas, dapat dinilai bahwa isu pemahaman budaya dan ketahanan peacekeeper serta keluarganya menjadi isu penting dalam peacekeeping era kontemporer. Dua hal ini, jika dikelola dengan baik pada akhirnya akan berkontribusi pada kesuksesan misi perdamaian PBB yang diemban oleh peacekeeper dari kalangan militer dan sipil. Untuk itu, perlu dilakukan upaya-upaya dalam rangka meningkatkan kecerdasan lintas budaya dan ketahanan bagi peacekeeper dan keluarganya agar misi-misi yang akan dilaksanakan oleh mereka di masa depan dapat menghasilkan outcome yang lebih baik daripada sebelumnya.

\section{METODE PENELITIAN}

Metode penelitian yang digunakan adalah metode penelitian kualitatif. Dalam penelitian kualitatif, peneliti merupakan instrumen utama dalam mengumpulkan dan menginterpretasikan data, dan alat-alat lain (jika memang ada) hanya sebagai alat bantu bagi peneliti. Penelitian dilakukan dengan mengkaji atau menginterpretasikan bahan tertulis berdasarkan konteksnya. Bahan tertulis tersebut dapat berupa catatan yang terpublikasi, buku teks, surat kabar, naskah, artikel dan penelitian terdahulu yang sejenis. Adapun tahapan-tahapan penelitian, yaitu melakukan pemilihan topik yang akan diteliti, kemudian melakukan eksplorasi informasi, menentukan fokus penelitian, mengumpulkan sumber data, membaca sumber data, menemukan teori-teori yang relevan digunakan untuk membedah data-data yang diperoleh, membuat analisis berdasarkan teori dan data yang diperoleh, kemudian membuat kesimpulan serta rekomendasi.

\section{HASIL DAN PEMBAHASAN}

Cultural Intelligence (Kecerdasan Budaya), Cross Cultural Competence (Kompetensi Lintas Budaya) dan Resilience (Ketahanan)

Earley \& Ang dalam Ang et al (2007) mendefinisikan cultural intelligence (kecerdasan budaya) sebagai kemampuan individu untuk berfungsi secara efektif dalam situasi budaya yang beragam. Kecerdasan budaya ini terdiri dari kecerdasan metakognisi, kecerdasan kognisi, kecerdasan motivasional dan kecerdasan perilaku. Kecerdasan lintas budaya dapat ditingkatkan melalui pelatihan dan pengalaman berada di budaya yang beragam. Selanjutnya menurut $\mathrm{Ng}$ et al (2005), empat unsur dalam kecerdasan budaya dapat ditingkatkan melalui pelatihan, yaitu pelatihan teknik modifikasi perilaku kognisi (refleksi, perencanaan dan selfmonitoring) untuk meningkatkan kecerdasan metakognisi, pelatihan kesadaran budaya tradisional untuk meningkatkan kecerdasan kognisi, pelatihan teknik goal setting untuk meningkatkan kecerdasan motivasional dan pendekatan dramaturgi untuk meningkatkan kecerdasan perilaku.

Sementara cross-cultural competence (kompetensi lintas budaya), terkhusus dalam profesi militer seperti yang dikemukakan Selmeski adalah kemampuan untuk memahami secara cepat dan akurat, kemudian secara pantas dan efektif untuk berinteraksi dengan individu dari budaya yang berbeda untuk mencapai hasil yang diinginkan. Selmeski menambahkan bahwa salah satu upaya yang dapat meningkatkan kompetensi lintas budaya adalah dengan program pengembangan yang meliputi aspek pengalaman, pelatihan, pendidikan dan pengembangan diri bagi personel militer (Selmeski, 2007). Pada dasarnya, kecerdasan budaya dan kompetensi lintas budaya merupakan dua konsep yang saling berhubungan satu sama lain (Li, 2020), oleh karenanya, keduanya harus dikembangkan secara bersamaan tanpa meninggalkan salah satu diantara keduanya.

Di sisi lain, Herrman et al (2011) menyatakan bahwa resilience (ketahanan) merupakan adaptasi positif atau kemampuan seseorang untuk menjaga dan mengembalikan kesehatan mental meskipun sedang mengalami kesulitan. Indikator ketahanan antara lain dapat dilihat dari performa individu, hubungan interpersonal, perilaku, emosi dan kompetensi sosial. Adapun sumber-sumber dari ketahanan seseorang antara lain adalah faktor pengasuhan, personal, biologis, lingkungan, teman-keluarga, sosial-ekonomi, budaya-spriritual dan kebijakan publik. Ketahanan ini dibutuhkan salah satunya oleh peacekeeper berkaitan dengan stresor yang mereka hadapi di tempat penugasan. Lamerson \& Kelloway (1996) menyatakan bahwa stresor yang mungkin ditemui oleh peacekeeper adalah combat stressors (misalnya eksposur langsung 
terhadap serangan dan vicarious exposure) serta contextual stressors (misalnya konflik peran/ambiguitas/peran yang berlebihan dan stresor yang berkaitan dengan keluarga dan keuangan).

Kemudian, penugasan peacekeeper ternyata tidak hanya berdampak pada ketahanannya sebagai individu, tetapi juga berdampak pada ketahanan keluarganya. Oleh karenanya, isu ketahanan keluarga menjadi penting dalam hal ini. Patterson (2002) menyatakan bahwa ketahanan keluarga merupakan kemampuan sistem sebuah keluarga untuk secara sukses mengelola situasi kehidupan mereka atau sebuah proses dimana sebuah keluarga dapat beradaptasi dan berfungsi secara kompeten menghadapi kesulitan atau krisis. Patterson lebih jauh memberikan indikator mengenai ketahanan keluarga, yaitu mengenai keanggotaan dan bentuk keluarga, dukungan ekonomi, asuhan, pendidikan dan sosialisasi, serta perlindungan kepada anggota keluarga yang rentan.

\section{Upaya Meningkatkan Kecerdasan Budaya dan Kompetensi Lintas Budaya untuk Peacekeeper}

Kecerdasan budaya dan kompetensi lintas budaya merupakan dua konstruk yang saling berhubungan. Seseorang dengan kecerdasan budaya dan kompetensi lintas budaya yang baik akan mempunyai kondisi kesehatan yang baik, penyesuaian diri yang baik, serta efektif dalam melaksanakan tugas. Kedua konstruk ini nyatanya dapat dilatih, baik melalui pembelajaran di kelas, pengalaman di lapangan dan didukung oleh keinginan seseorang untuk belajar (Kwantes \& Glazer, 2017).

Upaya meningkatkan kecerdasan budaya, terutama pada peacekeeper, dapat mengacu pada empat komponen kecerdasan budaya yaitu metakognisi, kognisi, motivasi dan perilaku. Kemampuan yang diperlukan oleh peacekeeper agar memiliki kecerdasan budaya berdasarkan empat komponen tersebut adalah pemahaman tentang norma interaksi sosial budaya tertentu (kognisi), strategi untuk memperoleh pemahaman tersebut dan juga untuk membangun serta mempertahankan hubungan dengan orang yang berbeda budaya (metakognisi), keinginan dan motivasi untuk secara percaya diri membentuk hubungan dengan orang yang berbeda budaya (motivasi) serta perilaku yang dapat diterima orang dengan budaya berbeda untuk selanjutnya membantu membuat hubungan semakin efektif (Ng, Ramaya, Teo, \& Wong, 2005).

Lebih spesifik, terdapat beberapa cara yang dapat digunakan untuk melatih empat komponen dari kecerdasan budaya tersebut bagi peacekeeper, misalnya pelatihan teknik modifikasi perilaku kognisi (refleksi, perencanaan dan self-monitoring) untuk meningkatkan kecerdasan metakognisi, pelatihan kesadaran budaya tradisional untuk meningkatkan kecerdasan kognisi, pelatihan teknik goal setting untuk meningkatkan kecerdasan motivasional dan pendekatan dramaturgi untuk meningkatkan kecerdasan perilaku (Ng, Ramaya, Teo, \& Wong, 2005). Pelatihan teknik modifikasi perilaku kognisi dapat dilakukan dengan metode agar peacekeeper meyakini bahwa dirinya mampu meningkatkan kecerdasan budayanya, antara lain dengan melakukan refleksi diri, merencanakan pembelajaran dan self-monitoring berupa feedback terhadap pembelajaran yang dilakukan. Pelatihan kesadaran budaya tradisional dapat dilakukan dengan memberikan pemahaman dan pengetahuan mengenai norma yang berlaku pada budaya tertentu. Pelatihan teknik goal setting dapat dilakukan dengan mendorong peacekeeper untuk memberikan target pada dirinya sendiri dalam memahami dan mempraktikkan nilai-nilai budaya tertentu. Terakhir, pelatihan dramaturgi atau role playing dapat dilakukan dengan metode bermain peran antar satu orang dengan orang lain dengan latar belakang budaya yang berbeda, untuk memberikan pemahaman sekaligus pengalaman kepada peacekeeper berada dalam lingkungan dengan budaya yang berbeda.

Peningkatan kecerdasan budaya juga dapat dilakukan dengan pengalaman bekerja di lingkungan dengan latar belakang budaya yang berbeda (multicultural work experience) yang pada akhirnya dapat meningkatkan efektivitas kepemimpinan lintas budaya. Namun demikian, pengalaman ini juga harus didukung dengan adanya pemahaman budaya yang lebih luas (expanded cultural cognition) dan identitas global (global identity) yang diperoleh seseorang dengan mengakui dirinya sebagai bagian dari dunia global akibat dari pengalaman bekerja di 
lingkungan dengan latar belakang budaya yang berbeda (Cheng, Mor, \& Morris, 2010).

Secara umum, seharusnya peacekeeper dengan intensitas penugasan yang lebih tinggi memiliki pemahaman budaya yang lebih luas dibandingkan dengan peacekeeper dengan intensitas penugasan yang lebih rendah. Namun demikian, jika peacekeeper tersebut tidak dapat menerima keberagaman budaya di tempat penugasannya, identitas globalnya tidak terbentuk. Dengan demikian, agar pengalaman penugasan dengan latar belakang budaya berbeda efektif untuk meningkatkan kecerdasan budaya, para peacekeeper sebelum pemberangkatan harus dibekali pemahaman mengenai keberagaman budaya di dunia, sehingga ketika menemui berbagai budaya yang berbeda di tempat penugasan, akan terbentuk identitas global dalam diri peacekeeper dan pada akhirnya berdampak pada meningkatnya kecerdasan budaya yang mereka miliki.

Sementara itu, upaya meningkatkan kompetensi lintas budaya di kalangan peacekeeper, khususnya militer pernah dibahas oleh Selmeski dengan mengambil contoh implementasinya pada Angkatan Bersenjata Kanada. Menurut Selmeski, kompetensi lintas budaya dapat ditingkatkan melalui pengalaman (experience), pelatihan (training), pendidikan (education), pengembangan diri (selfdevelopment) (Selmeski, 2007). Pengalaman mampu didapatkan peacekeeper dengan terbiasa hidup di lingkungan beragam, misalnya melakukan perjalanan ke luar daerah, tinggal di luar lingkungan compound militer, ikut serta dalam komunitas yang anggotanya heterogen, serta meningkatkan kesempatan bagi anggota militer untuk bertugas di luar negeri. Pelatihan dapat dilakukan dengan kursus bahasa dan familiarisasi budaya serta metode bermain peran (role playing). Pendidikan dapat dilakukan dengan memberikan pembelajaran yang lebih berat kepada unsur budaya seperti antropologi, sosiologi, keberagaman agama, psikologi. Terakhir, upaya pengembangan diri dapat dilakukan secara mandiri oleh para peacekeeper dalam rangka mendukung pengalaman, pelatihan dan pendidikan yang sudah didapat, misalnya dengan membaca dan menonton video. Pada prinsipnya, upaya pengembangan diri ini dilakukan untuk mengejar semua kompetensi yang dibutuhkan, yang mana kompetensi ini berada di luar kemampuan lembaga untuk memberikannya kepada peacekeeper.

\section{Upaya Meningkatkan Ketahanan bagi Peacekeeper}

Seperti yang dikemukakan sebelumnya, bahwa peacekeeper dalam masa penugasan rawan mengalami stress. Stress ini dapat digambarkan mempunyai tiga tahapan yaitu 1) persepsi mengenai ancaman terhadap diri, 2) proses membawa pemikiran/ide mengenai respon yang mungkin dilakukan terhadap ancaman tersebut dan 3) upaya mengatasi stress tersebut berupa ide mengeksekusi respon terhadap ancaman (Moldjord, Fossum, \& Holen, 2003). Secara umum, terdapat empat cara yang dapat dilakukan oleh peacekeeper untuk mengatasi stress dalam rangka meningkatkan ketahanannya yaitu 1) menangani stresor secara praktis, 2) strategi kognitif/internal, 3) mengurangi stres dengan didukung situasi dan lingkungan, serta 4) pendekatan personal (Moldjord, Fossum, \& Holen, 2003). Penanganan stresor secara praktis dapat dilakukan oleh peacekeeper dengan problem-focused coping. Dalam hal ini, peacekeeper dapat mengantisipasi stresor dengan melakukan perencanaan, tindakan langsung, meminta bantuan maupun mempertimbangkan tindakan lain. Selain problem-focused coping, cara yang dapat dilakukan adalah restraint atau menunda tindakan bagi peacekeeper hingga datang saatnya bagi peacekeeper untuk melakukan tindakan yang tepat. Kedua tindakan ini dapat mengurangi efek stresor terhadap peacekeeper karena peacekeeper dapat terlebih dahulu memikirkan cara yang paling efektif dan efisien untuk merespon stresor yang ada.

Strategi kognitif/internal dapat dilakukan dengan emotion-focused coping, yaitu strategi untuk tetap menjaga optimisme dan harapan oleh peacekeeper di tengah tekanan stresor. Upaya ini dilakukan di level kognitif (mengurangi emosi terhadap stresor) dan di level perilaku (mengalihkan perhatian dari stresor). Kemudian, strategi kognitif/internal juga dapat dilakukan dengan pengalihan, penghindaran maupun penyangkalan terhadap stresor, misalnya melakukan aktivitas yang dapat mengurangi stres sekaligus kecemasan. Kemudian, mengurangi stres dengan didukung situasi dan lingkungan 
dapat dilakukan dengan adanya dukungan sosial terhadap peacekeeper. Bagi peacekeeper, dukungan sosial terdekat yang dapat ia peroleh adalah hubungan baik antar orang di satuannya, loyalitas terhadap satuan dan moril satuan tersebut. Kohesifitas dan dukungan sosial dalam satuan terbukti dapat meminimalisir dampak stresor terhadap peacekeeper (Lamerson \& Kelloway, 1996). Terakhir adalah upaya pendekatan personal. Upaya ini lebih cenderung menjelaskan bagaimana seorang peacekeeper sebagai individu dapat menyikapi stresor dengan baik dan seimbang. Stresor yang muncul dapat dipersepsikan sebagai tantangan dan bukan ancaman. Kemampuan ini lazim disebut sebagai sense of coherence (SOC) yang membentuk pondasi bagi seorang peacekeeper untuk meminimalisir dampak stresor terhadap dirinya.

\section{Upaya Meningkatkan Ketahanan bagi Keluarga Peacekeeper}

Penugasan peacekeeper di daerah konflik yang menyebabkan dirinya terpisah dari keluarga, tidak dapat dipungkiri akan berpengaruh terhadap kualitas dan fungsionalitas keluarga peacekeeper tersebut. Oleh karena itu, isu ketahanan keluarga peacekeeper menjadi salah satu perhatian penting dalam peacekeeping kontemporer. Setidaknya terdapat lima risiko yang mungkin timbul akibat hal ini, yaitu 1) pemahaman yang kurang mengenai dampak penugasan dan combat stress terhadap orang tua dan anak serta harapan perkembangan yang tidak akurat, 2) terganggunya komunikasi keluarga, 3) terganggunya pengasuhan, 4) terganggunya struktur keluarga dan 5) kurangnya bimbingan terkait nilai-nilai kepercayaan di keluarga (Saltzman, et al., 2011). Oleh karena itu, diperlukan langkah-langkah yang efektif untuk mengatasi lima risiko tersebut.

Secara substansi, lima risiko yang mungkin dialami keluarga peacekeeper ini dapat diatasi dengan beberapa poin intervensi yang menjadi inti program FOCUS (Families Over Coming Under Stress) yang dikembangkan oleh UCLAHarvard development team. Poin-poin dari intervensi ini yaitu 1) penyediaan psikoedukasi dan bimbingan 2) pengembangan nilai-nilai bersama dalam keluarga, 3) peningkatan kesadaran dan pemahaman keluarga, 4) peningkatan rasa empati dan komunikasi dalam keluarga, 5) pengembangan keyakinan dan harapan dalam keluarga, 6) dukungan terhadap komunikasi yang terbuka dan efektif, 7) peningkatan kemampuan ketahanan keluarga pada aspek tertentu yang diperlukan dan 8) dukungan terhadap kepemimpinan orangtua yang efektif dan terkoordinasi (Saltzman, et al., 2011).

Pada tahap operasionalnya, program FOCUS dilakukan dalam enam hingga delapan sesi pertemuan antara trainer dengan keluarga peacekeeper. Dua pertemuan pertama dilakukan dengan pihak orangtua, dua pertemuan kedua dilakukan dengan pihak anak, pertemuan kelima dilakukan dengan orangtua untuk mempersiapkan pertemuan orangtua dan anak, kemudian selanjutnya adalah satu hingga tiga sesi pertemuan antara orangtua dan anak. Dalam dua sesi pertama, dilakukan assessment terhadap orangtua mengenai status orangtua dan keluarga terkait dengan stres pasca trauma, depresi, kecemasan, kesedihan, fungsi keluarga serta kesulitan dan kekuatan anak-anak mereka. Kemudian, dua sesi dengan anak-anak juga melingkupi susbtansi yang kurang lebih sama pada sesi dengan orangtua, memberikan arahan tentang program ini kepada mereka, menemukan kehawatiran dan harapan mereka, memulai psikoedukasi yang cocok dan menemukan nilainilai pribadi mereka. Setelahnya, dilaksanakan satu pertemuan kembali dengan orangtua untuk mempersiapkan pertemuan antara orangtua dan anak untuk melakukan review terhadap hal-hal yang dikemukakan anak-anak mereka. Terakhir, terdapat satu hingga dua pertemuan antara trainer dengan orangtua dan anak dalam rangka mengingatkan kembali nilai-nilai keluarga dan menyelesaikan permasalahan perbedaan interpretasi antar anggota keluarga. Di sesi ini, orangtua dan anak-anak mendiskusikan isu-isu penting dan kesalahpahaman, serta orangtua dapat menjawab pertanyaan dari anak-anak dengan jujur dan dengan cara yang pantas. Hal ini dilakukan agar sesi terakhir dapat terlaksana dengan baik antar orangtua dan anak-anaknya yang dikhususkan untuk melatih keterampilan tertentu dalam keluarga ini, termasuk penetapan tujuan kolaboratif, pemecahan masalah, penjadwalan waktu bersama, sikap peduli satu sama lain, dan mengembangkan strategi tingkat individu dan keluarga untuk menangani stressor (Saltzman, et al., 2011). 


\section{KESIMPULAN}

Di era peacekeeping kontemporer, mengemuka beberapa isu penting yang sebelumnya kurang menjadi perhatian para stakeholder untuk dikelola dengan lebih baik. Belajar dari kegagalan misi peacekeeping di Somalia, kecerdasan budaya dan kompetensi budaya merupakan dua kemampuan penting yang harus dimiliki oleh peacekeeper yang bertugas di lingkungan budaya yang berbeda. Di sisi lain, potensi peacekeeper terpapar stress selama penugasan di wilayah konflik dan dampak negatif yang mungkin dialami keluarga peacekeeper selama ia ditugaskan juga perlu menjadi perhatian, baik bagi PBB maupun negara-negara pengirim peacekeeper. Baik upaya peningkatan kecerdasan budaya, kompetensi lintas budaya hingga ketahanan peacekeeper dan keluarganya dapat dilakukan dengan pelatihanpelatihan. Namun demikian, diperlukan komitmen dan kemauan politik yang kuat dari para stakeholder terkait agar pelatihan-pelatihan ini dapat dilaksanakan dengan sistematis, komprehensif dan berkesinambungan untuk mendukung berbagai misi perdamaian yang masih dan akan dilaksanakan oleh PBB.

Di tingkat akademis, penelitian-penelitian mengenai urgensi kecerdasan budaya, kompetensi lintas budaya hingga ketahanan peacekeeper dan keluarganya dalam misi peacekeeping $\mathrm{PBB}$ perlu dilakukan lebih mendalam untuk lebih jauh menemukan masalah-masalah yang muncul dalam era peacekeeping kontemporer dan solusi yang mungkin digunakan berkaitan dengan hal tersebut. Di tingkat praktis, PBB melalui Department of Peacekeeping Operations perlu menyusun Standard Operating Procedure (SOP) yang khusus mengatur mengenai upaya peningkatan kecerdasan budaya, kompetensi lintas budaya hingga ketahanan peacekeeper dan keluarganya baik pada masa pre-deployment, deployment maupun post-deployment.

\section{DAFTAR PUSTAKA}

Ang, S., Dyne, L. V., Koh, C., Ng, K. Y., Templer, K. J., Tay, C., \& Chandrasekar, N. A. (2007). Cultural Intelligence: Its Measurement and Effects on Cultural Judgment and Decision Making, Cultural
Adaptation and Task Performanc. Management and Organization Rev, 335-371.

Cheng, C.-Y., Mor, S., \& Morris, M. (2010). Global Identity and Expanded Cultural Cognition as Antecedents for Global Leadership. Academy of Management Journal, 1-37.

Duffey, R. (2000). Cultural Issues in Contemporary Peacekeeping. International Peacekeeping, 142-168.

Herrman, H., Stewart, D., Granados, N. D., Berger, E., Jackson, B., \& Yuen, T. (2011). What Is Resilience. Canadian Journal of Psychiatry, 258-265.

Ho-Won, J. (2008). Understanding Conflict and Conflict Analysis. London: Sage Publications.

Huntington, S. (1996). Clash of Civilization. New York: Simon \& Schuster.

Kwantes, C. T., \& Glazer, S. (2017). CrossCultural Competence and Cultural Intelligence in the Workplace. Culture, Organizations, and Work, 95-101.

Lamerson, C. D., \& Kelloway, E. K. (1996). Towards a Model of Peacekeeping Stress: Traumatic and Contextual Influences. Canadian Psychology, 195204.

Li, M. (2020). An Examination of Two Major Constructs of Cross-Cultural Competence: Cultural Intelligence and Intercultural Competence. Elsevier, 1-6.

Miall, H., Ramsbotham, O., \& Woodhouse, T. (2011). Contemporary Conflict Resolution. Cambridge: Polity.

Moldjord, C., Fossum, L. K., \& Holen, A. (2003). Coping with Peacekeeping Stress. Dalam T. W. Britt, \& A. B. Adler, The Psychology of The Peacekeeper: Lesson from the Filed (hal. 169-184). London: Praeger. 
Murray, L. (2021, April 10). UNOSOM. Diambil kembali dari Encyclopaedia Britannica: https://www.britannica.com/topic/UNOS $\mathrm{OM}$

Ng, K. Y., Ramaya, R., Teo, T. M., \& Wong, S. F. (2005). Cultural Intelligence: Its Potential for Military Leadership Development. International Military Testing Association, (hal. 1-14). Singapore.

Nye, J., \& Welch, D. A. (2017). Understanding Global Conflict and Cooperation. Boston: Charlyce Jones Owen.

Patterson, J. M. (2002). Integrating Family Resilience and Family Stress Theory. Journal of Marriage and Family, 349360.
Saltzman, W. R., Lester, P., Beardslee, W. R., Layne, C. M., Woodward, K., \& Nash, W. P. (2011). Mechanisms of Risk and Resilience in Military Families: Theoretical and Empirical Basis of a Family-Focused Resilience Enhancement Program. Clin Child Fam Psychol Rev, 213-230.

Selmeski, B. R. (2007). Military Cross-Cultural Competence: core concepts and individual development. US Air Force Culture and Language Center, 1-41.

United Nations. (2021, April 10). Where we operate. Diambil kembali dari United Nations Peacekeeping: https://peacekeeping.un.org/en/wherewe-operate. 